\title{
Beneficial Effects of Achillea Millefolium and Aesculum Hippocastanum Extracts on Glutamate Excitotoxicity in the Primary Cultured Neurons
}

\author{
Ferah Okkay ${ }^{1}{ }^{1}$, Okkay $\mathrm{U}^{2 *}$, Cicek $\mathrm{B}^{3}$, Yesilyurt $\mathrm{F}^{2}$, Yilmaz $\mathrm{A}^{2}$ and \\ Hacimuftuoglu $\mathrm{A}^{2}$ \\ ${ }^{1}$ Department of Pharmacology, Ataturk University Faculty of Pharmacy, Erzurum- \\ Turkey
}

2Department of Pharmacology, Ataturk University Faculty of Medicine, Erzurum-

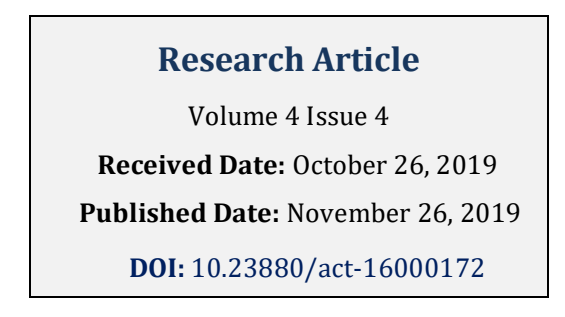
Turkey

${ }^{3}$ Department of Physiology, Ataturk University Faculty of Medicine, Erzurum-Turkey

*Corresponding author: Ferah Okkay I, Department of Pharmacology, Ataturk University Faculty of Medicine, TR 25100 Erzurum, Turkey, Tel: +90 54284666 57; Email: ufukokkay@atauni.edu.tr

\section{Abstract}

Achillea millefolium and Aesculum hippocastanum extracts are natural products which have antioxidant effects. It is well known that neurotoxicity caused by glutamate excitotoxicity is linked to oxidative stress. In this study we investigated the potential neuroprotective effects of Achillea millefolium and Aesculum hippocastanum extracts against glutamate excitotoxicity in the primary cultured neuron cells. According to our MTT results Achillea millefolium and Aesculum hippocastanum had neuroprotective effects against glutamate excitotoxicity in the cortical neuron cells. Achillea millefolium and Aesculum hippocastanum were showed to inhibit the glutamate induced TOC levels and also showed to increase TAC levels which decreased by glutamate excitotoxicity. We have demonstrated that Achillea millefolium and Aesculum hippocastanum protected against glutamate induced excitotoxicity at different doses in the primary cultured neuron cells via antioxidative pathway.

Keywords: Neuron Cell Culture; Glutamate Excitotoxicity; Achillea Millefolium; Aesculum Hippocastanum

\section{Introduction}

Glutamate is the major excitatory neurotransmitter in the central nervous system. Glutamatehas important roles in many neurophysiological functions [1]. However, that excessive release of glutamate lead to neuronal dysfunction and neuronal death and it is known as excitotoxicity [2]. Glutamate excitotoxicity had been shown to have a pivotal role in many neurodegenerative 
diseases such as Alzheimer's disease (AD), Parkinson's disease (PD), chronic pain and Huntington's disease (HD) $[3,4]$. Reactive oxygen species (ROS) play important roles in the cascade of pain associated with glutamate [5]. Glutamate excitotoxicity and oxidative stress are very valuable targets to search new drug molecules and natural products for various neurodegenerative diseases and chronic pain [3]. It seems as a good strategy to investigate the glutamate excitotoxicity and oxidative stress together for new therapies [4].

The Achillea millefolium is a member of the Achiella species which has highly bioactive compounds and so they have so many different therapeutic applications. Some Achillea extracts had been shown to have antioxidant, and antimicrobial, properties [6,7]. And also they can be useful in wound healing, and also can be used as antidiabetic, anti-inflammatory, antineoplastic, antihypertensive, and antihyperlipidemic [6,8-11]. Also it is known they had antioxidant effects but it is still remain unclear whether they had beneficial effects on excitotoxicity [6].

Aesculum hippocastanum can be used in chronic venous insufficiency, especially in hemorrhoids, topical ulcers and cancer [12-17]. They also exhibit antioxidative, antigenotoxic, anti-inflammatory, anti-oedematous and anti-exudative activities $[6,18,19]$. In this study we have examined the potential protection of achillea millefolium and aesculum hippocastanum extracts against glutamate excitotoxicity at different doses. We found that the neurotoxicity caused by glutamate in the primary cultured neuron cells was inhibited by both Achillea millefolium and Aesculum hippocastanum. Then we showed their total oxidant and antioxidant capacities on glutamate excitotoxicity to understand their beneficial effects further. Our results showed that achillea millefolium and aesculum hippocastanum can be useful in preventing glutamate excitotoxicity via increasing antioxidant capacity and reducing the oxidant capacity.

\section{Material and Methods}

\section{Primary Cultures of Cortical Neurons}

Primary cortical neuron culture was prepared from 10 to $12 \mathrm{~d}$ old Sprague-Dawley rats (Animal center of Ataturk University, Erzurum, Turkey). In brief, the cerebral cortex were dissected from neonatal SD rats placed into $\mathrm{Ca}^{2+}-\mathrm{Mg}^{2+}$ - free HBSS containing $0.125 \%$ trypsin. After digestion for $20 \mathrm{~min}$ at $37^{\circ} \mathrm{C}$, after that, the tissue was subsequently triturated with a series of fire- polished Pasteur pipettes in basic medium containing DMEM and fetal bovine serum (FBS, $10 \%$ ). Then the cells were centrifuged at $800 \mathrm{rpm}$ for $10 \mathrm{~min}$ for removing the medium. After that, cells were was plated onto polylysinecoated plates and maintained neurobasal medium supplemented with $2 \%$ B27 and $0.5 \mathrm{mM} \mathrm{L}$ - glutamine, penicillin and streptomycin $(10 \mathrm{U} / \mathrm{ml}$ and $10 \mathrm{mg} / \mathrm{ml}$, respectively). Cells were grown at $37{ }^{\circ} \mathrm{C}$ with $5 \% \mathrm{CO}_{2}$ humidified atmosphere. On the day following, the media were totally changed with fresh culture medium and then half of the medium was replaced every two days. Experimental treatments were performed on the eighth day later after cells were branched and had reached a certain maturity [20].

\section{Glutamate-Mediated Excitotoxicity and Cell Treatment}

To assess Achillea millefolium and Aesculum hippocastanum for neuroprotective effects against glutamate-induced excitotoxicity damage, 10 to $12 \mathrm{~d}$ old cortical cell cultures were used. Primary cortex neurons after obtained enough branches (neurons) the $10^{-5} \mathrm{mM}$ concentration of glutamate were added to each well except negative control group for $10 \mathrm{~min}$ to modeling glutamate excitoxicity. Achillea millefolium and Aesculum hippocastanum extracts were dissolved in $\% 0.9 \mathrm{NaCl}$ to provide a final $100 \mu \mathrm{M}$ stock solution. These stock solutions were used to prepare different concentration of treatment media. The primary cortical neurons were treated 1, 5, 25, 50 and $100 \mu \mathrm{g} / \mathrm{mL}$ of Achillea millefolium and $5,25,50,75$ and $100 \mu \mathrm{g} / \mathrm{mL}$ of Aesculum hippocastanum added after glutamate toxicity model were established.

\section{Determination of Cell Viability}

Cell viability was determined by using 3-[4,5dimethylthylthiazol-2-yl]-2,5-diphenyltetrazolium

bromide (MTT) assay (Sigma, USA) (1). Primary cortical neuron cells were seeded in culture well plate for overnight and were allowed to attach for $24 \mathrm{~h}$ before the induced glutamate excitotoxicity and treatment with Achillea millefolium and Aesculum hippocastanum. Then, glutamate excitotoxicity induced and medium containing different concentrations of Achillea millefolium and Aesculum hippocastanum administered each well (in triplicates) at $37^{\circ} \mathrm{C}$ with $5 \% \mathrm{CO}_{2}$ for one day. After $24 \mathrm{~h}$ treatment the medium was removed and $30 \mu \mathrm{L}$ MTT solution ( $5 \mathrm{mg} / \mathrm{ml}, 10 \mu \mathrm{l}=10 \%$ of total well volume) was added to each well and incubated at $37^{\circ} \mathrm{C}$ for $4 \mathrm{~h}$. The medium was then removed, and the formazan crystals 
dissolved with $100 \mu \mathrm{L}$ of DMSO for $5 \mathrm{~min}$. The absorbance was measured at $570 \mathrm{~nm}$ by a microplate reader (Biotech, Germany). Cell viability was stated to a percentage of the control (untreated cells) and calculated according to the following equation [21].

Cell viability $(\%)=[$ A570 $($ sample $) /$ A570 $($ control $)] \times$ $100 \%$.

\section{Biochemical Parameters}

Total antioxidant capacity: Total antioxidant capacity (TAC) was determined by using a commercial kit (Rel Assay Diagnostic, Cat No: RL0024; Gaziantep, Turkey) according to the manufacturer's instructions. Antioxidants in the sample reduced the dark blue green colored 2, 29-azinobis-(3-ethyl-benzothiazoline-6sulfonic acid (ABTS) radicals to a colorless reduced ABTS form. The ABTS is decolorized by antioxidants depending on their concentrations and antioxidant capacities and alteration in color was measured as a change in absorbance (TAC at $660 \mathrm{~nm}$ ). The results are state as mmol Trolox Equiv/L [22].

Total oxidant capacity: Total oxidant capacity (TOC) was determined by using a commercial kit (Rel Assay Diagnostic, Cat No: RL0024; Gaziantep, Turkey) according to the manufacturer's instructions. The ferric ion formsa colored complex with chromogen in an acidic medium. The color intensity, which can be measured spectrophotometrically (absorbance at and TOC at 530 $\mathrm{nm}$ ), is related to the total amount of oxidant molecules present in the sample. The assay was calibrated with hydrogen peroxide $\left(\mathrm{H}_{2} \mathrm{O}_{2}\right)$. Results were expressed in terms of $\mu \mathrm{mol} \mathrm{H}_{2} \mathrm{O}_{2}$ Equiv/l [23].

\section{Statistical Analysis}

The statistical analysis was performed by means of one-way analysis of variance (ANOVA) and Tukey's HSD using the SPSS 20.0 software. $p<0.05$ were considered as statistically significant and highly significant, respectively.

\section{Results}

To form glutamate toxicity we applied $10^{-5} \mathrm{mM}$ concentration of glutamate on neuron cells for 10 minutes and after that we applied our molecules. And the we measured cell viability by MTT assay. Our results showed in Figure 1.

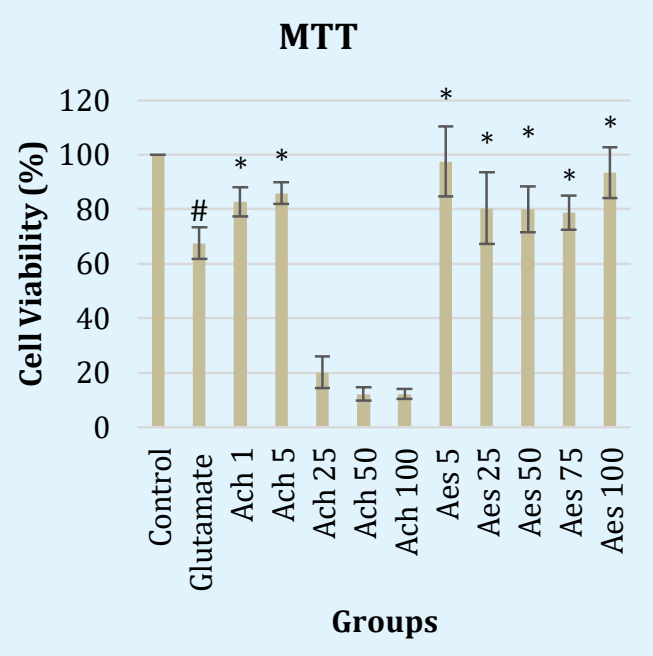

Figure 1: MTT results of experimental groups. \# Means Glutamate showed statistically significance difference from Control group $(\mathrm{p}<0,05)$ and * means these groups showed statistically significance difference from Glutamate group $(\mathrm{p}<0,05)$.

Glutamate showed excitotoxicity on neuron cell according to our MTT results. (The significance is $p<0,05$ ) And cell viability was partially rescued by Achillea Millefolium extract at doses 1 and $5 \mu \mathrm{g} / \mathrm{mL}$ and by Aesculum hippocastanum extracts at doses 5, 25, 50, 75 and $100 \mu \mathrm{g} / \mathrm{mL}$ (The significance is $\mathrm{p}<0,05$ ) and in order to understand underlying mechanism of cell viability ratios we measured TAC and TOC values of each cell culture well. Results of TAC and TOC values are showed in Figures $2 \& 3$.

\section{TAC}

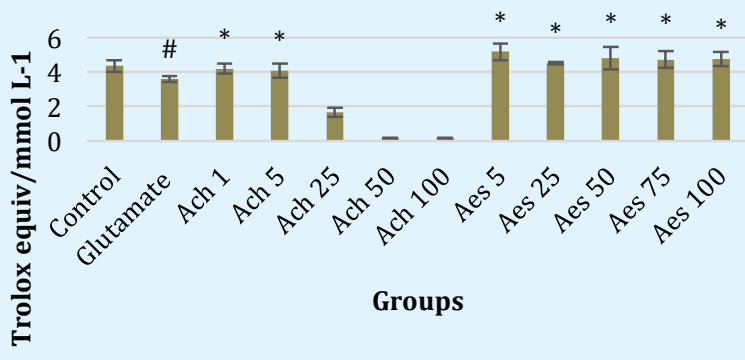

Figure 2: TAC values of experimental groups. \# Means Glutamate showed statistically significance difference from Control group $(p<0,05)$ and * means these groups showed statistically significance difference from Glutamate group $(\mathrm{p}<0,05)$. 
Glutamate decreased TAC values by excitotoxicity and TAC values were increased by Achillea Millefolium extract at doses 1 and $5 \mu \mathrm{g} / \mathrm{mL}$ and by Aesculum hippocastanum extract at doses 5, 25, 50, 75 and $100 \mu \mathrm{g} / \mathrm{mL}$.

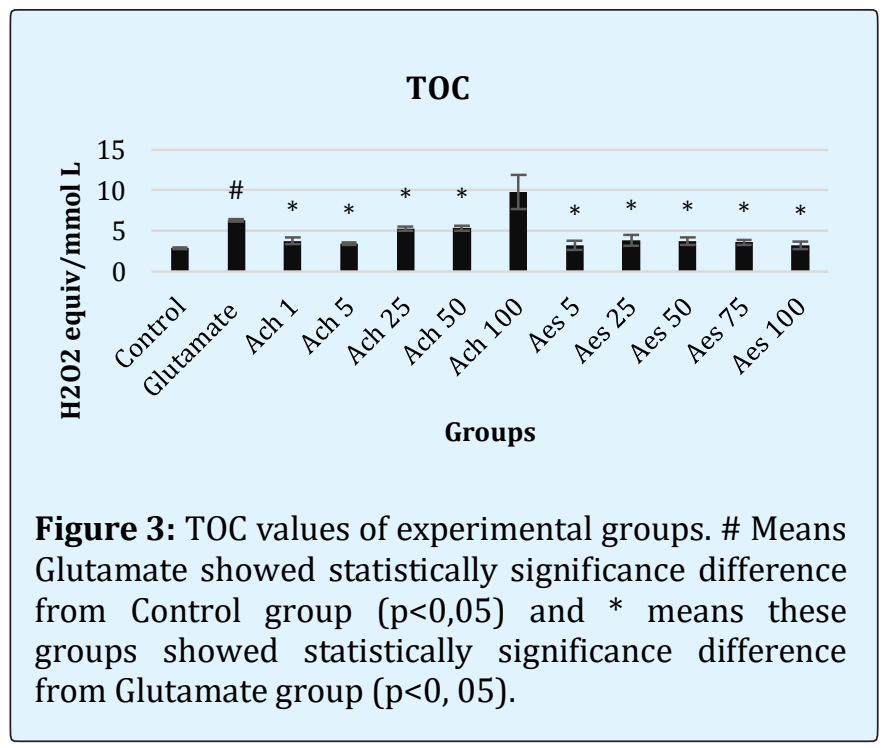

Glutamate increased TOC values by excitotoxicity on neurons and TOC values were decreased by Achillea Millefolium extract at doses 1, 5, 25 and $50 \mu \mathrm{g} / \mathrm{mL}$ and by Aesculum hippocastanum extract at doses 5, 25, 50, 75 and $100 \mu \mathrm{g} / \mathrm{mL}$.

\section{Discussion}

Neurodegenerative diseases are still needed to better understanding and different treatment options other than what we have now. The neurodegenerative disorders include Alzheimer's disease, Parkinson's disease, Huntington's disease, chronic pain and amyotrophic lateral sclerosis which affect millions of people globally. Although many research studies about this arena, the neurodegenerative diseases remain without cure and we only have symptomatic treatment options about these common disorders. One of the most attractive treatment choices is about chemical molecules and natural products which have antioxidant properties. Cell culture studies are very important to investigate new treatment options. In our study, we demonstrated that neurotoxicity caused by glutamate was attenuated by natural products Achillea millefolium and Aesculum hippocastanum in the primary cultured neurons. Our data are consistent with the studies about these natural products antioxidant effects.
Glutamate induced neuronal death is associated with the production of oxidative stress in the neurons [24]. In this study we showed that glutamate induced oxidative stress in the primary cultured neuron cells which is consistent with literature. Pretreatment with Achillea millefolium and Aesculum hippocastanum prevented oxidative parameters caused by glutamate in the neurons and also these natural products increased antioxidant parameters, confirming the neuroprotection of Achillea millefolium and Aesculum hippocastanum. We measured TAC and TOC levels and for both of these parameters we found Achillea millefolium and Aesculum hippocastanum had antioxidant effects on glutamate induced neurotoxicity. These results suggest that the antioxidant role of Achillea millefolium and Aesculum hippocastanum might play a critical role against glutamate excitotoxicity.

In conclusion, we have demonstrated that Achillea millefolium and Aesculum hippocastanum protected against glutamate induced excitotoxicity at different doses in the primary cultured neuron cells. And also, in this study we showed that the protective effect of Achillea millefolium and Aesculum hippocastanum was mediated through attenuation of oxidative stress. Thus our study supports the hypothesis that Achillea millefolium and Aesculum hippocastanum are potential targets to treat neurodegenerative disorders; further investigations must be done for this aim.

\section{References}

1. Meldrum BS (2000) Glutamate as a neurotransmitter in the brain: review of physiology and pathology. J Nutr 130(4): 1007S-1015S.

2. Zhou Y, Danbolt NC (2014) Glutamate as a neurotransmitter in the healthy brain. J Neural Transm (Vienna) 121(8): 799-817.

3. Dong XX, Wang Y, Qin ZH (2009) Molecular mechanisms of excitotoxicity and their relevance to pathogenesis of neurodegenerative diseases. Acta Pharmacol Sin 30(4): 379-387.

4. Cong L, Cao C, Cheng Y, Qin XY (2016) Green Tea Polyphenols Attenuated Glutamate Excitotoxicity via Antioxidative and Antiapoptotic Pathway in the Primary Cultured Cortical Neurons. Oxid Med Cell Longev 2016: 2050435.

5. Parenti C, Marrazzo A, Arico G, Parenti R, Pasquinucci L, et al. (2014) The antagonistic effect of the sigma 1 


\section{Advances in Clinical Toxicology}

receptor ligand (+)-MR200 on persistent pain induced by inflammation. Inflamm Res 63(3): 231237.

6. Bali EB, Acik L, Elci P, Sarper M, Avcu F, et al. (2015) In vitro anti-oxidant, cytotoxic and pro-apoptotic effects of Achillea teretifolia Willd extracts on human prostate cancer cell lines. Pharmacogn Mag 11(2): S308-315.

7. Ali N, Shah SW, Shah I, Ahmed G, Ghias M, et al. (2011) Cytotoxic and anthelmintic potential of crude saponins isolated from Achillea Wilhelmsii C. Koch and Teucrium Stocksianum boiss. BMC Complement Altern Med 11: 106.

8. Akkol EK, Koca U, Pesin I, Yilmazer D (2011) Evaluation of the Wound Healing Potential of Achillea biebersteinii Afan. (Asteraceae) by In vivo Excision and Incision Models. Evid Based Complement Alternat Med 2011.

9. Conforti F, Loizzo MR, Statti GA, Menichini F (2005) Comparative radical scavenging and antidiabetic activities of methanolic extract and fractions from Achillea ligustica ALL. Biol Pharm Bull 28(9): 17911794.

10. Kupeli E, Orhan I, Kusmenoglu S, Erdem Y (2007) Evaluation of anti-inflammatory and anti-nociceptive activity of five anatolian Achillea species. Turk J Pharm Sci 4(2): 89-99.

11. Asgary S, Naderi GH, Sarrafzadegan N, Mohammadifard N, Mostafavi S, et al. (2000) Antihypertensive and antihyperlipidemic effects of Achillea wilhelmsii. Drugs Exp Clin Res 26(3): 89-93.

12. Sirtori CR (2001) Aescin: pharmacology, pharmacokinetics and therapeutic profile. Pharmacol Res 44(3): 183-193.

13. Pittler MH, Ernst E (1998) Horse-chestnut seed extract for chronic venous insufficiency. A criteriabased systematic review. Arch Dermatol 134(11): 1356-1360.

14. Suter A, Bommer S, Rechner J (2006) Treatment of patients with venous insufficiency with fresh plant horse chestnut seed extract: a review of 5 clinical studies. Adv Ther 23(1): 179-190.

Okkay U, et al. Beneficial Effects of Achillea Millefolium and Aesculum Hippocastanum Extracts on Glutamate Excitotoxicity in the Primary Cultured Neurons. Adv Clin Toxicol 2019, 4(4): 000172.
15. Methlie CB, Schjott J (2009) Horse chestnut--remedy for chronic venous insufficiency. Tidsskr Nor Laegeforen 129(5): 420-422.

16. Konoshima T, Lee KH (1986) Antitumor agents, 82. Cytotoxic sapogenols from Aesculus hippocastanum. J Nat Prod 49(4): 650-656.

17. Niu YP, Li LD, Wu LM (2008) Beta-aescin: a potent natural inhibitor of proliferation and inducer of apoptosis in human chronic myeloid leukemia K562 cells in vitro. Leuk Lymphoma 49(7): 1384-1391.

18. Costantini A (1999) Escin in pharmaceutical oral dosage forms: quantitative densitometric HPTLC determination. Farmaco 54(11-12): 728-732.

19. Rehn D, Unkauf M, Klein P, Jost V, Lucker PW (1996) Comparative clinical efficacy and tolerability of oxerutins and horse chestnut extract in patients with chronic venous insufficiency. Arzneimittelforschung 46(5): 483-487.

20. Tian T, Zeng J, Zhao G, Zhao W, Gao S, et al. (2018) Neuroprotective effects of orientin on oxygen-glucose deprivation/reperfusion-induced cell injury in primary culture of rat cortical neurons. Exp Biol Med (Maywood) 243(1): 78-86.

21. Mosmann $T$ (1983) Rapid colorimetric assay for cellular growth and survival: application to proliferation and cytotoxicity assays. J Immunol Methods 65(1-2): 55-63.

22. Erel O (2004) A novel automated direct measurement method for total antioxidant capacity using a new generation, more stable ABTS radical cation. Clin Biochem 37(4): 277-285.

23. Erel O (2005) A new automated colorimetric method for measuring total oxidant status. Clin Biochem 38(12): 1103-1111.

24. Reynolds IJ, Hastings TG (1995) Glutamate induces the production of reactive oxygen species in cultured forebrain neurons following NMDA receptor activation. J Neurosci 15(5): 3318-3327.

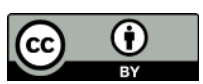

Copyright(C) Okkay U, et al. 